\title{
Culture And Universal Professional Values In Global Organizations: Is There A Divergence Or Convergence Of Cultural Values?
}

\author{
Robert Nieves, (Email: RobertNieves@adelphia.net), Nova Southeastern University \\ Bahaudin G. Mujtaba, (Email: mujtaba@sbe.nova.edu), Nova Southeastern University \\ Pedro F. Pellet, Nova Southeastern University \\ Frank Cavico, Nova Southeastern University
}

\begin{abstract}
This article presents and discusses the theory of universal human values, the universal human values of people across cultures, and how culture and values impact organizations. This article reviews the history and research into human values, culture, and behavior, followed by reviews of Hofstede's Cultural Dimensions and Schwartz and Bilky's Theory of Universal Human Values. A strong connection exists between these theories and their related empirical research, not only chronologically, but also theologically and methodologically. The subjects are presented in a temporal sequence. Thus, the work of Professor Gert Hofstede is presented first; the work of Schwartz, Bilsky, is more recent, but strongly linked to prior research by Hofstede on values and culture. The objective is to improve ones understanding of work-related values, culture, and the impact that values may have on individuals in different cultural environments that are found in international organizations. This study tests to see if there is a difference in individualism scores of Mexican and American engineers when compared to Hofstede's original study in 1980. This study also looks at the Mexican and American engineer samples to see if their scores on Hofstede's cultural dimensions show a correlation with the scores on Schwartz's culture-level dimensions. The study attempts to determine if there is a divergence or convergence of cultural values. Findings of the study are reported.
\end{abstract}

\section{UNIVERSAL HUMAN VALUES, CULTURE, ATTITUDES, AND BEHAVIOR}

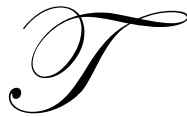

he study of human values has become increasingly important to researchers trying to understand and measure the impact that changing values have on behavior, culture, and organizations of human beings. Today's international firms have employees with different cultural backgrounds and value systems all over the world. These firms are trying to better understand workers' attitudes and practices to improve the performance of the international organizations and the effectiveness of their management.

Meglino and Ravlin (1998) explained that firms and individuals would benefit from a better understanding of the relationship between values of the employees and the corporate culture. Corporate Culture is defined by the values of corporate managers and subordinates. A strong corporate culture is possible only if the employees' values are in agreement with those of the firm. Athos and Coffey $(1968$, p. 100) state that "values" mean ideas about what is desirable. Kluckhohn et al. (1962, p. 369) state, "value is a conception, explicit or implicit of the desirable which influences the selection from available modes, means, and ends of action." 
Culture has to do with the way people live and behave in a social and organizational setting. Culture has many definitions. Hofstede (1994, p. 5) defines culture as "the collective programming of the mind which distinguishes the members of one group or category of people from another." He observed that collective mental programming, although not directly observable, is shared within and between groups of people, and that managerial groups shared this collective programming. Hofstede (1980) found profound differences in the attitudes and behaviors of managers and subordinates across cultures. The variance in work values was explained by national culture, and not so much by profession, title, gender, or age.

Hofstede $(1980,1994)$ recognized that values are the foundation of culture. He emphasized that an understanding of values is critical to understand behavior.

\section{HOFSTEDE'S CULTURAL DIMENSIONS}

Hofstede (1980) defined four dimensions of culture that described fundamental similarities and differences in human behavior, attitudes and decision-making for culture. The four dimensions were masculinity/femininity, power distance, individualism / collectivism, and uncertainty avoidance. Masculinity is defined as the opposite of femininity. Masculinity stands for success, competition, assertiveness, good performance, service to others, and brotherhood (Hofstede, 1992). Femininity stands for tenderness, warm relationships, caring, and modesty.

Hofstede (1997, p. 28) defines Power Distance as "the extent to which the less powerful members of institutions and organizations within a country expect and accept that power is distributed unequally." He asserts that societies have different levels of power distance. People that live in societies with a high degree of power distance desire the inequities between members of societies. Those people in societies with low power distance try to lessen the inequalities.

Individualism is the tendency to pursue one's goal independently from one's own reference group. Hofstede (1997) states that Individualism "pertains to societies in which the ties between individuals are loose: everyone is expected to look after himself or herself and his or her immediate family." Furthermore, Hofstede defines Collectivism "as its opposite pertains to societies in which people from birth onwards are integrated into strong, cohesive ingroups, which throughout people's lifetime continue to protect them in exchange for unquestioning loyalty (p. 51)." He explains that in individualistic societies identity is based on the individual, communication is very low context, people look after themselves and their nuclear family; whereas in a collective society, identity is based on the social network of the individual, communication is high-context, people are protected by an extended family in exchange for loyalty.

Hofstede (1997, p. 113) defines Uncertainty Avoidance as "the extent to which members of a culture feel threatened by uncertain or unknown situations." Uncertain avoidance refers to a personal preference for situations that are structured or unstructured with well-defined rules of behavior. Hofstede and Bond (1988) defined a fifth dimension that was labeled long-term/short-term orientation. Table 1.1 presents the result of Hofstede's four dimensions. The fifth cultural dimension refers to an individual's emphasis towards the past, present, or future. When short-term orientation is towards the present and the past, members of a culture tend to respect traditions, "save face," and meet social obligations. When long-term orientation is towards the present and the future, then there is a tendency towards perseverance and saving for the future. Hofstede conducted the IBM Study by country and cultural dimension, but did not include long-term/short-term orientation in the study (Hofstede, 1980). 
Table 1.1- Hofstede's IBM Study of 40 Countries (Hofstede, 1980)

\begin{tabular}{|c|c|c|c|c|c|}
\hline Country & Abbreviation & PD & UA & HDV & MAS \\
\hline Argentina & (ARG) & 49 & 86 & 46 & 56 \\
\hline Australia & (AUI) & 36 & 51 & 90 & 61 \\
\hline Austria & (AUT) & 11 & 70 & 55 & 79 \\
\hline Belgium & (BEL) & 65 & 94 & 75 & 54 \\
\hline Brazil & (BRA) & 69 & 76 & 38 & 49 \\
\hline Canada & $(\mathrm{CAN})$ & 39 & 48 & 80 & 52 \\
\hline Chile & (CHI) & 63 & 86 & 23 & 28 \\
\hline Colombia & (COL) & 67 & 80 & 13 & 64 \\
\hline Denmark & (DEN) & 18 & 23 & 74 & 16 \\
\hline Finland & (FIN) & 33 & 59 & 63 & 26 \\
\hline France & (FRA) & 68 & 86 & 71 & 43 \\
\hline Germany -FR & (GER) & 35 & 65 & 67 & 66 \\
\hline Great Britain & $(\mathrm{GBR})$ & 35 & 35 & 89 & 66 \\
\hline Greece & (GRE) & 60 & 112 & 35 & 57 \\
\hline Hong Kong & (HONK) & 68 & 29 & 25 & 57 \\
\hline India & (IND) & 77 & 40 & 48 & 56 \\
\hline Iran & (IRA) & 58 & 59 & 41 & 43 \\
\hline Ireland & (IRE) & 28 & 35 & 70 & 68 \\
\hline Israel & (ISR) & 13 & 81 & 54 & 47 \\
\hline Italy & (ITA) & 50 & 75 & 76 & 70 \\
\hline Japan & $(I A P)$ & 54 & 92 & 46 & 95 \\
\hline Mexico & (MEX) & 81 & 82 & 30 & 69 \\
\hline Netherlands & (NET) & 38 & 53 & 80 & 14 \\
\hline Norway & (NOR) & 31 & 50 & 69 & 8 \\
\hline New Zealand & (NZL) & 22 & 49 & 79 & 58 \\
\hline Pakistan & (PAK) & 55 & 70 & 14 & 50 \\
\hline Penu & (PER) & 64 & 87 & 16 & 42 \\
\hline Philippines & (PHI) & 94 & 44 & 32 & 64 \\
\hline Portugal & (POR) & 63 & 104 & 27 & 31 \\
\hline South Africa & $(S A F)$ & 49 & 49 & 65 & 63 \\
\hline Singapore & (SIN) & 74 & 8 & 20 & 48 \\
\hline Spain & $(\operatorname{SP} A)$ & 57 & 86 & 51 & 42 \\
\hline Sweden & (SWVE) & 31 & 29 & 71 & 5 \\
\hline Switzerland & (SWT) & 34 & 58 & 68 & 70 \\
\hline Taiwan & (TAN) & 58 & 69 & 17 & 45 \\
\hline Thailand & (THA) & 64 & 64 & 20 & 34 \\
\hline Turkey & (TUR) & 66 & 85 & 37 & 45 \\
\hline USA & (USA) & 40 & 46 & 91 & 62 \\
\hline Venezuela & (VEN) & 81 & 76 & 12 & 73 \\
\hline Yugoslavia & (YUG) & 76 & 88 & 27 & 21 \\
\hline
\end{tabular}

\section{SCHWARTZ'S CULTURE-LEVEL DIMENSIONS}

Schwartz (1994) performed research on work-related values on the cultural level based on previous findings. He emphasized culture-level value dimensions instead of individual indirect expression of work-centrality cultural values. The Schwartz culture-level value scale has predicted behaviors, attitudes, and beliefs. Schwartz (1996) was able to effectively predict a value measurement for voting behavior, interpersonal cooperation, and outgroup contact readiness, which validated his culture-level value scale.

Schwartz (1992, 2000) has defined three bipolar dimensions of culture: mastery versus harmony, embeddedness versus autonomy, and hierarchy versus egalitarianism. These dimensions of culture affect the relationship of humanity to the natural and social world, the boundary between the individual and the group, and the responsible behavior that preserves the social fabric (Schwartz and Bardi, 1997).

The mastery-harmony dimension addresses the issue of regulating the relationship of humanity to the natural and social world. Mastery promotes active self-assertion in order to master, to exploit, and to change the natural and social environment to achieve personal or group goals. Ambition, competence, daring, and success are its related values. On the other hand, harmony promotes engaging the environment harmoniously as one. Promoting the environment, unity with nature, and peace in the world are its related values. 
The embeddedness-autonomy dimension addresses the boundary and relationship between the individual and the group. The relationship in embedded societies involves participation and pursuit of the group's way of life, and identifying oneself with the group. The key values in this dimension are security, social order, tradition, and wisdom. Individuals are part of the collective network and seek the meaning of life through social relationships and their groups (Schwartz and Sagiv, 2000).

The relationship in autonomous societies involves expressing the individual's internal attributes and uniqueness. Schwartz and Sagiv (2000) describe two types of autonomy: intellectual and affective. Intellectual autonomy motivates individuals to follow their ideas and path through values like broadmindedness, creativity, and curiosity. Affective autonomy motivates individuals to go after positive experiences through values like excitement, pleasure, and variety.

The hierarchy-egalitarianism dimension addresses the responsible behavior of the individual that preserves the social fabric. Hierarchy assigns roles to individuals to insure responsible behavior and legitimizes the unequal distribution of power, resources, and roles. Authority, humility, social power, and wealth are its related values. Egalitarianism encourages individuals to consider one another as moral equals who share basic interests and needs as human beings. Equality, honesty, responsibility, and social justice are its related values. The welfare of others is encouraged to precede one's own selfish interest in life, and a voluntary commitment towards a genuine concern for others (Schwartz and Sagiv, 2000).

Schwartz (1994) reanalyzed Hofstede's data and replicated Hofstede's intercorrelations. Moreover, he found correlations between Hofstede's ratings for the four dimensions in the IBM study and his value types. Schwartz's and Hofstede's teacher samples had correlations based on the same 23 nations, and the student samples had correlations on 22 nations. Schwartz's (1994) cross-cultural study consisted of 86 samples from 41 cultural groups in 38 nations. The most significant correlations included a one-tailed test, with $\mathrm{p}<0.05$, and $\mathrm{r}$ as the correlation, that resulted in the findings presented in Table 1.2.

Table 1.2: Schwartz's And Hofstede's Teacher/Student Correlations (Schwartz, 1994)

\begin{tabular}{|l|c|c|}
\hline \multicolumn{1}{|c|}{ Overlapping Dimensions } & r (Student Sample) & r (Teacher Sample) \\
\hline Power Distance \& Affective Autonomy & -0.83 & -0.45 \\
\hline Power Distance \& Intellectual Autonomy & -0.49 & +0.45 \\
\hline Power Distance \& Conservatism & +0.70 & +0.56 \\
\hline Power Distance \& Egalitarianism & -0.47 & +0.43 \\
\hline Masculinity \& Mastery & & +0.46 \\
\hline Uncertainty Avoidance \& Harmony & & +0.53 \\
\hline Individualism \& Affective Autonomy & +0.85 & -0.56 \\
\hline Individualism \& Intellectual Autonomy & +0.48 & -0.51 \\
\hline Individualism \& Egalitarianism & +0.45 & \\
\hline Individualism \& Conservatism & -0.66 & \\
\hline Individualism \& Hierarchy & & \\
\hline
\end{tabular}

\section{Study Methodology And Results}

The authors of this study surveyed professionals in Mexico and the United States, with engineers of companies that manufacture, distribute, or service electrical equipment. The study used a comparative research design because it sought to compare the cultural scores for engineers in Mexico and the United States to identify whether the level of technology and its corresponding level of development influence cultural convergence. A comparative analysis of engineers' cultural values was conducted on two samples of engineers in the electrical equipment business of the energy market. Technology and its corresponding level of development is a force that may be working toward cultural convergence by helping to narrow cultural differences; technology is becoming more uniform across countries, and thus may be promoting more uniform cultural values. 
Research data was collected from engineers using two questionnaires: the Schwartz Value Survey (SVS) and Hofstede's VSM 94. Only respondents who are citizens of Mexico or the United States and had an engineering degree were asked to take the survey. The surveys were conducted in Mexico and the United States, and the choice of these two countries allowed for cultural diversity and minimized language barriers, with the validated surveys available in English and Spanish. This study reports on the following two hypotheses:

Hypothesis 1: The difference in individualism scores between Mexican engineers and American engineers will be less than the differences found in the Hofstede's original study.

Hypothesis 2: For the Mexican and the American engineer samples, the scores on Hofstede's cultural dimensions will show significant correlation with the scores on Schwartz's culture-level dimensions.

This study and its results add to the existing knowledge of cultural convergence or divergence. First, the study provides a strong indication that there is factual evidence of cultural convergence between the Mexican engineer sample and the United States sample, and that cultural differences are lessening with respect to Individualism. With regard to Hofstede's cultural dimension of Individualism, Mexican engineers scored 66.49 (versus 30 in 1980) and American engineers had a score of 89.15 (versus 91 in 1980).

Schwartz's Score for Mexican and American engineers were reported without too much difference. For American engineers $(n=47)$, the Schwartz scores are:

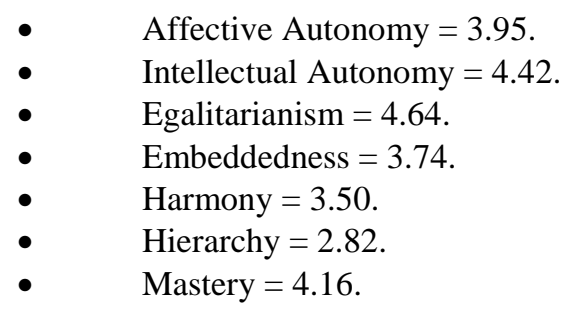

For Mexican engineers $(\mathrm{n}=37)$, the Schwartz scores are:

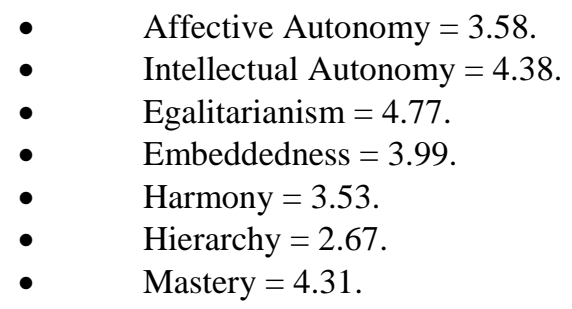

The fact that there are no statistically significant relationships between Hofstede's cultural dimensions and individual demographic variables is explained by Schwartz's (1995) findings that the country variable helps explain three times the variance when compared to other individual demographic variables (Schwartz, 1990, 2000). This study suggests that national culture does not represent the strongest and only force driving individual work values towards divergence. Technology and its corresponding level of development seem to be significant forces acting on the convergence-divergence dimension of cultural values. The study also suggests that there is a correlation between Schwartz's culture-level dimensions and Hofstede's cultural dimensions. Overall, the results of this study confirmed that Hofstede's and Schwartz's cultural dimensions are conceptually linked and both provide a conceptual system to explain and test the concept of national culture and its effect on cultural values. 


\section{CONCLUSIONS AND IMPLICATIONS}

With regard to the question of cultural divergence or convergence, this study found a convergence on the individualism scores of Mexican and American engineers when compared to Hofstede's original study in 1980. One can say that the past 25 years has decreased the gap between the individualism scores, as determined by Hofstede's cultural dimensions, between various professional populations in Mexico and the United States. Hofstede's original study used professional IBM employees in the sample and this study used certified or college graduate engineers. Despite the limitations, both population of employees worked for multinational corporations and seem to be comparable. This study also found that there is a correlation between the Mexican and American engineer sample scores on Hofstede's cultural dimensions and on Schwartz's culture-level dimensions.

All in all, research has indicated how cultures differ in their choice of, and the significance given to, values, and how superiors and subordinates differ in their values across cultures, as well as how values tend to remain and resist change in a specific national culture or society. There is research evidence that national cultures vary and that strategic management, managerial attitudes, leadership, and personnel management vary across national cultures. These differences between national cultures and managerial attitudes affect job performance. National culture is the employee's central organizing principle to approach and understand work, and thus provides expectations of how the employee might be treated by others. National culture provides the set of rules to act, and the set of preferred outcomes to compare from, before an action is taken. Employees are likely to prefer management practices that are consistent with their work values and may reject those practices that are not.

National cultural values that are not reinforced by management practices are more likely to predict behavior and performance, because congruent management practices are consistent with existing behavioral expectations and routines that transcend the workplace (Early, 1994). The congruence between management practices and the characteristics of the national culture results in better performance. The implication of this to international firms is very significant because international firms need to adapt to national culture to reach high performance goals. A significant competitive advantage will likely be achieved from the correct adaptation and alignment of the firm's management practices with the national culture, or outside environment, the strategy systems, and the structure of the company.

As communications and movement of people and goods across national borders grow at an ever-increasing pace, markets become more integrated. Some scholars have in fact heralded such trends to globalization as among the most important and compelling in business today, with far-reaching consequences for organizational structure, management decision-making, and effective competitive strategies in world markets. Consequently, it becomes important to understand how these changes are impacting the microenvironment of a country (Craig, Douglas and Grein, 1992).

As countries' macroeconomic environments converge, these countries will offer similar context for research, and similar strategies and administrative procedure will be employed. The growth of communication, commerce, and travel between these countries, and the advent of globalization and market integration suggest that countries will become more similar in their economic and national culture environments. Technology is bringing people closer together and making distances shorter.

\section{REFERENCES}

1. Athos, A.G. and Coffee, R.E. (1968). Behavior in organizations: A multidimensional view. Englewood Cliffs, NJ: Prentice-Hall.

2. Craig, C. Samuel, Douglas, Susan P., and Grein, Andreas. (1992). Patterns of convergence and divergence among industrialized nations. Journal of International Business Studies, 23(4), 773-787.

3. Early, P. Christopher. (1994). Self or Group? Cultural effects of training on self-efficacy and performance. Administrative Science Quarterly, 39, 89-117.

4. Hofstede, G. (1980). Culture's Consequences: International differences in work-related values. Beverly Hills, CA: Sage. 
5. Hofstede, G. (1992). Cultural constraints in management theories. Paper presented at the Academy of Management Studies, 22(4), 347-357.

6. Hofstede, G. (1994). Cultures and organizations: Intercultural cooperation and its importance for survival. Hammersmith: Harper Collins Publishers.

7. Hofstede, G. (1997). Cultures and Organizations: Software of the Mind, New York, McGraw Hill.

8. Hofstede, G. and Bond, M.H. (1988). The Confucius connection. From cultural roots to economic growth. Organizational Dynamics, 5-21.

9. Kluckhohn, C. (1962). Values and value-orientation in the theory of action. In T. Parsons and E.A. Shils (Eds.), Toward a general theory of action, 388-433. New York: Harper and Row.

10. Meglino, B.M. and Ravlin, E.C. (1998). Individual values in organizations: concepts, controversies, and research. Journal of Management, 24(3), 352-390.

11. Nieves, R. and Mujtaba, B. G. (June 2006). The Effect of Cultural Values, Professional Engineering Cultures, and Technology on International Joint Ventures in Mexico and the United States. International Business and Economics Research Journal, Vol. 5, Num. 6.

12. Nieves, R. and Mujtaba, B. G. (2006). Cultural Values, Engineering Culture, Technology, and International Joint Ventures. Chapter in Privatization and Market-Based Leadership in Developing Economies: Capacity Building in Afghanistan. By B.G. Mujtaba. Pages 271-290. Llumina, Coral Springs, U.S.A.

13. Schwartz, S.H. (1992). Universal in the content of and structure of values: Theoretical advances and empirical tests in 20 countries. In M.P. Zanna (Ed.), Advances in experimental social psychology (Vol. 24, pp. 1-65). San Diego, CA: Academic Press.

14. Schwartz, S.H. (1994). Beyond individualism-collectivism: New cultural dimensions of values. In U. Kim, H.C. Triandis, C. Kacitcibasi, S.C. Choi and G. Yoon (Eds.), Individualism and collectivism: Theory, methods, and applications. Thousand Oaks, CA: Sage.

15. Schwartz, S.H. (1996). Value priorities and behavior: Applying a theory of integrated value systems. In C. Seligman, J.M. Olson, and M.P. Zanna (Eds.), The psychology of values: The Ontario symposium (Vol. 8, 124). Mahwah, NJ: Erlbaum.

16. Schwartz, S.H. and Bardi, A. (1997). Influences of adaptation to communist rule on value priorities in Eastern Europe. Political Psychology, 18, 385-410.

17. Schwartz, S.H. and Sagiv, L. (2000). National cultures: Implications for organizational structure and behavior. In N.N. Ashkanasy, C. Wilderom, and M.F. Peterson (Eds.), The handbook of organizational culture and climate, 417-436, Newbury Park, CA: Sage. 
NOTES 